Fecha de recepción: marzo 2012 Fecha de aceptación: junio 2012 Versión final: marzo 2013

\section{Habitancia y Comunidades de Sentido. Complejidad Humana y Educación. Considera- ciones acerca del acto educativo en Diseño}

Viviana Polo Flórez *

\begin{abstract}
Resumen: ¿Que se enseña, y que se aprende? La educación con sus diversas vertientes como la reflexión sistemática, compendio de métodos formativos para un contexto particular, en si misma se ha convertido en una corriente de posibilidades pragmáticas, eficientes y concluyentes, que han enmarcado al sujeto en un contenedor de conocimientos, como entes operantes desde las reacciones guiadas por un impulso o caso de estudio, y no en un sistema que propenda complementariedad, unidad y beneficio general, desde la perspectiva sensible y vital. En este gran espectro de posibilidades, la validez del enseñar y el aprender esta en reconocer como premisa fundamental a un sujeto, a un hombre o mujer de una sociedad, que se haya confrontado desde el aula a poseer más que conocimientos y el eje central de su quehacer, de su rol, y se haya estructurado desde la esencia en la educación y de la condición humana. Este escrito, plantea desde la óptica del diseño una reflexión en torno a los elementos de estructura y poder, que se dan desde las aulas de diseño y desde los roles de quienes las ocupan (DocenteEstudiante), en donde la emergencia creativa, busca no solo la diferenciación de los resultados tangibles -producto de un proceso de diseño- , sino el reconocimiento de los sujetos que por medio del acto educativo ayudan a ser a los otros.
\end{abstract}

Palabras clave: desarrollo humano - Diseño - Educación - heterarquía.

[Resúmenes en inglés y portugués en la página 303]

${ }^{(*)}$ Diseñadora Industrial (UTJL). Magister en Educación: Desarrollo Humano (USB-Cali). Docente e investigadora de la Facultad de Arquitectura, Arte y Diseño, Programa Diseño de Vestuario (USB- Cali).

El cuento es muy sencillo. Usted nace, contempla atribulado el rojo azul del cielo el pájaro que emigra, el torpe escarabajo que su zapato aplastará valiente. Usted sufre, reclama por comida y por costumbre por obligación llora limpio de culpas extenuado hasta que el sueño lo descalifica. Usted ama, se transfigura y ama por una eternidad tan provisoria que hasta el orgullo se le vuelve tierno y el corazón profético se convierte en escombros. Usted aprende y usa lo aprendido, para volverse lentamente sabio para saber que al fin el mundo es esto, en su mejor momento una nostalgia, en su peor momento un desamparo y siempre, siempre un lío. Entonces, usted muere (Curriculum, Mario Benedetti). 


\section{Introducción}

¿Cuál sería la finalidad, de ver desde el acto educativo al ser humano primero como un sujeto, que verlo solo desde un rol especificado como docente o estudiante? Las condiciones socioculturales han demarcado las condiciones del sujeto desde su posibilidad del hacer, lo que indica de por si un proceso de aprendizaje, en donde los actores son constructores permanentes de de las realidades futuras (sujetos en educación), que como acto forma un constante tejido de supervivencia para la complejidad multidimensional citada al inicio de estas líneas, y que ponen en paralelo el principio de educación y el de la pedagogía.

En este proceso -el del aprendizaje-se enfocan las formas pedagógicas que determinaran como el sujeto en educación -como receptor- repercutirá no solo los conocimientos, sino también su visión de la vida y su quehacer técnico y profesional, los denominados Analistas Simbólicos ${ }^{1}$. La educación como acto político, plantea la posibilidad real de la comprensión de los momentos históricos y la finalidad a través de la homogenización de conocimientos y la función heterogénea por medio de la especialización, para la sociedad. En el sentido más estricto, no se pueden generalizar ni los actos pedagógicos ni las estructuras educativas, ya que el contexto y las disciplinas marcan rumbos específicos para cada necesidad, pero conformando el proceso de transposición, y de figuración adaptativa, para beneficio común toda la estructura de una sociedad especifica, puede educarse de diversos modos. Así el acto político de la educación, permite no solo el establecimiento ideológico del Estado y la transmisión de los elementos culturales, además permite la participación activa del ser-humano, más allá de la habilidad técnica, desde un complexus de pensamiento, reflexión y proposición, enmarcadas en el futuro, en la acción, el beneficio y la satisfacción de construir, elevar, preservar, y crear desde las bases de lo heterogéneo el futuro real de la sociedad: Sujetos en acción, sujetos en el estado constante, enriquecedor e infinito de esta construcción social.

La educación por sí sola, no es la única responsable para la conformación de una sociedad, pero si es el medio desde el cual todos los sujetos con sus extensas complejidades pueden desarrollarse, confrontarse, indagarse, complementarse para trascender, crear, crecer, enseñar y aprender. $\mathrm{Y}$ en esta ocupación, de momentos, espacios, información e intercambios para el desarrollo van emergiendo las condiciones del sentido de ser, habitar y permanecer.

La habitancia2 (el sentido del "con" y "para" el mundo desde el sujeto), permite la comprensión de ese parámetro referencial dado como el acto político de dar y recibir, de conformarse, de completarse e incompletarse en una continuidad, y desde este sentido la configuración de un sujeto que se forma desde la plataforma e intercambio con otros es de vital importancia para hacer la relevancia de la particularidad del acto educativo. Desde los elementos que componen este devenir, el sujeto en formación como epicentro de las conformaciones epistémicas de la creatividad pone su subjetividad y emocionalidad sobre los planos de acción.

Desde esta construcción los componentes y variables de especificidad y contribución, hacen que los elementos de conformación adquieran de manera "corpórea" roles y asignaciones, que en el desarrollo de este escrito se intentara posicionar, ordenar y relacionar más allá del sentido de la categoría y la ordenación de poder. Desde las comunidades de sentido, el pensamiento y la sensibilidad, como procesos de categorización son establecidos como procesos mentales, que se ubican en niveles que a veces resultan inalcanzables para la elaboración de la conciencia de quienes educan y se educan, teniendo como referencia el uso de parámetros, que acortan los 
desafíos epistémicos y de las construcciones cotidianas del sentido creativo. Diversos ámbitos disciplinares cada uno con su marcada epistemología, plantean ámbitos de problematización que responden a desafíos de diversos tipos que como mundos en escala se van adaptando y articulando para el desarrollo común. Sin embargo es pertinente a partir de los lenguajes que habitan los entramados simbólicos culturales, de creación y configuración de la vida, hacer una mirada de las bases que configuran tensiones/relaciones desde las comunidades de sentido, con un enfoque y con la necesidad de entender como surgen los "asuntos" de creación en las aulas donde reside como premisa la creatividad, y como base de la complejidad ${ }^{3}$.

Cita Morín: "mientras la ciencia de la ciencia de inspiración cartesiana iba muy lógicamente de lo complejo a lo simple, el pensamiento científico contemporáneo intenta leer la complejidad de lo real bajo la apariencia simple de los fenómenos. De hecho no hay fenómeno simple" (Solana Ruiz, 2005, p. 28).

Esto nos muestra que los entramados que se conforman en las aulas, en los actos educativos, en los intercambios para el conocimiento superan las estancias espacio-temporales, conformando las condiciones del ser y su potencial.

\section{Sentido de Habitancia y complejidad humana}

En los actos del desarrollo de los sujetos en dependencia con la permeabilidad de los procesos educativos, la emergencia de la búsqueda de sí mismo en su lógica complejidad indica los sentidos de reconocer elementos identitarios, de singularidad y de colectividad. Por ende, en los procesos inherentes a los sistemas tradicionales de la educación, un poco en oposición al desarrollo humano, se busca primero afuera lo que se debería hallar adentro. Así, los tejidos sociales heterogéneos hacen que el sujeto se deje gobernar por las políticas tradicionales de cómo ejecutar sus procesos, pero en consecuencia un sujeto inconforme, pero desmotivado a encontrar en esta dilación, la opción de una búsqueda de conocimiento y recursividad. Y esto se hace manifiesto en los procesos educativos, que desde diferentes frentes ahondan por las metódicas establecidas como modelos de repercusión en donde el sujeto hace parte de un capital pero no es el capital.

Esta definición, pretende sopesar el hecho de la particularidad y singularidad que se pone en juego en el acto educativo, y que tiene que ver con el hecho de la diferenciación, la motivación personal, las características generales de la reciprocidad y los espacios de conformación del sujeto consigo mismo y en relación con los otros.

Aquí es donde la emergencia del sujeto se hace visible desde los procesos de interacción en el aula de diseño, relevantes a los procesos donde la creatividad se pone en juego y en donde los elementos de la creación se argumentan desde didácticas subyacentes y que están en búsqueda de la prefabricación y lo previsible.

Es así, que en las didácticas formativas desde el diseño y en particular en lo encuentros que proveen el desarrollo de la identidad creativa y proyectual, existen consonancias y disonancias en la búsqueda de esta particularidad. Los casos en donde la disonancia se torna más explícita, es aquella donde las premisas son pre-establecidas y los modelos de ejecución impuestos para llegar a un resultado -desde la denominación de metodologías de enseñanza del diseño: Talleres-. En estos procesos, el estudiante evidencia su intención de querer ir hasta el final, y casi como 
una manía el leer de adelante para atrás basándose en un posible resultado, muchas veces sin darse la opción de indagar como se dio el inicio, el principio de las cosas y como redundancia mitificada, el tratar de descubrir que el inicio no está al principio, el inicio puede estar en una fase, o en el salto brutal y drástico de la transformación.

En este punto es en donde la complejidad del pensamiento debe tomar la injerencia pertinente, no como un modelo que se aplica, se repite y se petrifica, sino como el elemento de la comprensión que cada sujeto tiene un entramado particular, que a modo de sustrato ha de referir una identidad especifica, y que desde el diseño podría nombrarse como un estilo, una señal particular para crear, como la estampa de quien está creando a partir del descubrimiento de su sustrato, así:

Las concepciones y denominaciones del mundo del ser-sujeto están ancladas en sus asignaciones simbólicas, entendidas como remanentes de su identidad y su aprendizaje de la vida en las referencias normativas, dadas por su exterior y configuradas en sus mapas mentales, como bases reales y de validación de su realidad (Polo, 2011).

En el otro frente del proceso, está quien funge de guía y regulador, y quien debe generar las consonancias apropiadas para el devenir creador. En esta interacción didáctica se han venido transponiendo las nociones del tiempo y espacio, que arrastra la costumbre y que a modo de formula de ejecución se plantea como metodología de la interacción didáctica. El mundo del dialogo, es la base de la construcción epistémica y así la definición del construir, sugiere que los elementos que se relacionan entre sí, ponen sus características de particularidad, las inquietudes y movilizaciones, los deseos y expectativas, y también los desaciertos e interrogantes de la vida. Estos son elementos que dan completud, a una estructura que argumenta los devenires de la formación, en donde los roles se intercambian, las direcciones se complementan y los mundos se crean.

Así como en un lenguaje analógico, el dialogo de la conformación, sugiere los términos de la Incompletud ${ }^{4}$ en donde las posturas se yuxtaponen, se rotan, se complementan para poder reconocer un reflejo de lo que se busca primero afuera, para poderlo hallar adentro, y desde esta, cada una de las perspectiva proponer los puntos de partida consecuentes, como la síntesis de la complejidad-complexa, de la integralidad y la secuencia de conformación y la creación. Los fundamentos de la educación, han empoderado la posición del maestro y han centrado los visos de territorialidad, en el carácter y repercusión de su devenir y acontecimiento en el aula, este como un entendimiento de organización de categorías, pone en la mesa la discusión acerca de dónde surge esta organización y porque se sigue entendiendo este lineamiento estructural de la misma manera.

Al ver los componentes de un proceso didáctico desde un aula de diseño, en donde las finalidades son presuntuosas y donde el ejercicio de crecer es algo implícito, pero no comprendido se pone a consideración las siguientes ideas para comprender la finalidad de un ejercicio didáctico desde y para el diseño desde el aula:

1. Ver lo que se es hoy, lo que rodea el contexto, el entorno y el ser, para poder determinar cuáles han sido las razones que permiten reflexión, más allá de las finalidades de estudiar casos. 
2. Abrir a consideración, la multiplicidad de intercambios de la construcción epistémica (desde el dialogo docente-estudiante) para dar validar el esquema de: armar, crear y estructurar en colectivo y al unisonó para la repercusión de un trabajo en equipo, un trabajo compartido.

En este proceso se aprende a re-encontrar algunos verbos y a re-significar algunas vanas teorías que apenas habían rozado la inquietud de los sentidos, de las racionalidades y de la emoción.

Desde la mención del argumento de la diada Completud-Incompletud sugerido por (Skliar, 2007, p. 64): se plantean tres movimientos diferentes y solidarios, desde la mirada pedagógica de la construcción:

a) que la Incompletud del otro -sea este otro: la infancia, la juventud, la discapacidad, raza, generación, género, clase social, etnia, cuerpo, sexualidad, etc.-; se configura como un dato inicial, habitual, naturalizado.

b) Que toda la Incompletud debe ser vista, necesariamente como negativa;

c) Que es función básica y crucial de la educación promover el completamiento del otro, es decir, que la educación es como el completamiento del otro.

Al hacerse una unidad en la completud-Incompletud se encarnan, los halos de vida que resuenan en los escenarios inmediatos, así como el de los ecos del pasado -y desde el acto educativo la suma de muchos pasados historiográficos- que permite al alma y espíritu encarnarse de modo corpóreo en una idea, en un proyecto que se va conformando y posicionando. Y así, desde la lógica de un proceso al posicionarse se hace la incorporación. Esta co-inclusión, toma de una gran red, las cuerdas que sujetaran la vida y cada una, como creencias y la visión que ha de determinar lo que sigue después de cada existencia, esto es el aprendizaje.

Así este aprendizaje incorporado, se puede divisar como la fortaleza de la estructura, esa estructura que se alza y se enfoca en múltiples direcciones y posibilidades, aquí es en donde se activa la Fe de la creación, del proyecto que va mostrando su génesis, como principio y motivación, sumada al cúmulo de información intensa y suave que determina un posible alcance y que como una energía, toma lo encarnado para potenciarlo y desplegarlo, abrirlo como flor, darle vida después de la vida, resonancia, eco, trascendencia, posibilidad.

Iniciado este camino ya no hay vuelta atrás al dar este paso y esta asunción y al abrir los ojos como alas, el viaje ha iniciado, y permite la proyección, el proyectar y ser la implicación de poner un pie en el mañana, en el futuro. En donde podría ser encarnada la idea, ser o no material el proyecto, pero en donde radica la trascendencia, la herencia, el paso de una vida al triunfo de lo inmortal, y un no a la tumba del olvido, la idea en la proyección se hace trascendente, los medios son los que le permiten la vida.

El proyectar y ser, sugiere una posibilidad infinita de posiciones: proyectar y ser como imagen, como palabra, como aliento o como encarnación (materialización). Desde una idea, tener la capacidad de generar algos, que desde diversas perspectivas sean capaces de volar o ser raíz, si vuela la luz del sol (como energía primaria y vital) permitiría, generar desde arriba una infinidad de "estampados" visibles e invisibles; Si se proyecta desde el suelo, poder ser la base, la raíz, que soporta las posibilidades, que da múltiples opciones de vida, y que permite alimentar, y ser punto de encuentro entre muchos insumos vitales. Desde ahí, desde arriba, abajo, atrás o adelante, según como se oriente el hecho del despliegue prolijo, fecundo, profundo, desde el 
crear y ser, construyendo al ser, origina el eco más abierto, y vivo como la libertad. Aquí se ata la vida desde una complejidad estructural, la suma y resta de posibilidades, lenguas y visiones. Al libertar-se, se divisa el punto de partida, y su juego convergente y divergente, sus amplitudes y estrecheces, su inicio y su fin.

El juego de la recreación de la vida y de las ideas, no está en una sola persona desde este sentido de completud-Incompletud, donde todo va buscando una conformación y denominación. Este juego, esta polifonía se funda en el ayer, el hoy y en la decisión de las bases de la fundación de los mundos del mañana, de quienes serian su protagonistas, en qué momento bajo qué circunstancias, con que falencias y riquezas, con qué recursos y con cuales derroches. Esto es proyectar, idear, crear.

El Diseño, puede ser o no ser una respuesta, ser o no ser un idioma, puede ser o no proceso, esa es la idea desde el acto educativo Heterarquico, desde el aula de diseño: El indagar-nos, el confrontar-nos él armar-nos, para que todos pero cada uno sea un punto de partida, una necesidad convergente que redunde y que insista, que enfatice la posibilidad más vital, la divergencia de la libertad del descubrimiento, la creación, la proyección.

\section{Sentido Heterarquico - Comunidad y Sentido}

Cuando el sujeto entra en el proceso de socialización, contando con las cosas y circunstancias que se aprende desde pequeño, todos los actores que se involucran en este proceso determinan lo que está bien o mal asignando escalas de valores, lo que es asumido como un conocimiento explicito o tácito y que da la relevancia a la conciencia del saber. Estos procesos marcan, delinean y configuran el espectro de las posibilidades del ser y el hacer, en donde el sujeto en el supuesto altruista elige cual es el rumbo que forma y los trayectos que va trazando. En estas construcciones devienen lo pragmático y emocional del sujeto, deviene el sustrato y lo prospectivo y también deviene la idea y la palabra. Estas bases son invisibles e ineludibles para la conformación del que se Es como sujeto.

Citando a Rogers \& Rosenberg,

Los estudiantes aprenden en realidad en un medio abierto. Aprenden sobre la emoción y la importancia del descubrimiento, sobre sus propias aptitudes y limitaciones, sobre autodisciplina y responsabilidades. También aprenden hechos ¿Cuántos? ¿Quién sabe? Solo sé que aprenden algunos hechos (...) Me hace sentirme a gusto el saber realmente una cosa y tener la profunda certeza de que estamos aprendiendo. Apertura... ¡ha de vivenciarse, vivirse, hacerse (Rogers \& Rosenberg, 1981, p. 163). 5

Se visibiliza esta estructura que se va conformando desde diferentes frentes, y que como claves de significación colectiva y singular van armando los puentes entre el desarrollo del sujeto y la sociedad. Aquí, el sentido de la alineación de los roles y la comunicación, la formación y la conformación toman posiciones de especificidad que desde los métodos educativos han planteado diversos ordenes. 
Así desde los modelos clásicos de la enseñanza, la generalidad de esta alineación ha sido caracterizada por una cadena de poderes donde se centra en el docente el poder y la determinación de lo que se genera como conocimiento. Modelos que han dado orígenes a métodos, que van modelando según su contextualización adaptaciones de normativa pero no de poder. En esta lógica, se antepone el valor de quien da, y se va fluctuando sobre el valor de quien recibe. No en vano desde el espectro de las bases del pensamiento occidental, en donde las "posturas" ideológicas y comportamentales a la vez que se entrelazan, se especializan dan visibilidad a la congruencia del proceso aprender/enseñar y enseñar/aprender. La conformación de los sistemas hace prever ciertos órdenes, características, comportamientos y resultados. Todos estos como una conformación rizomatica, que nos conforma y condiciona. Los ritmos sobre los cuales se forman los sujetos, van perfilando las mecánicas de operación, del modo tal de quien las transmite.

Sin pretender entrar en una discusión acerca de los modelos de lenguaje, y todas sus posibles vertientes, el planteamiento de un emisor y receptor se sigue validando con ciertas adaptaciones, y descubrimientos. Y en se punto las competencias se van formando desde los modelos que se transmiten y se asumen. Desde el diseño, en donde el dialogo ha de ser construido desde las bases del pensamiento creativo es factible hacer una acotación, respecto a quienes y en qué orden se encuentran (o desencuentran) aquellos que hacen parte del acto educativo. Si referimos nuevamente la educación como un acto político, se debe reconocer que los valores que forman al sujeto entran en el juego de la conformación; pero también lo que son sus conformadores externos, las jurídicas fundamentales y los contextualizadores epocales. Así, el rescatar el modelo clásico de aquel "que transmite" su sapiencia queda desde el lente del diseño como una clase de pugna entre el modelo clásico generalizado, y el modelo de pensamiento y aprendizaje divergente que es propio del diseño. Sin embargo y en las propias aulas de diseño:

Las pedagogías se dirigen a la eficiencia informativa, con fórmulas que supuestamente garantizan el éxito, a través del desarrollo de propuestas materiales que -con nuestros ideales de creadores-creemos necesarias para el medio. Ello, dentro de una óptica antropocentrista -cómo sirve los objetos hombre- que no reconoce la antropoplastia como base de nuestros modelos de educación que permitiría descubrir al sujeto, potenciar su desarrollo y esencia humana (Polo, 2011).

La estructura de formación no es estática, ni desde los sujetos ni desde los entornos, ni en la orientación de la función, ni desde la finalidad. Es imprescindible una regulación así como también una apertura, una mirada amplia y un reconocimiento en la definición de las rutas de poder. La heterarquía, evoca una alineación en distinto orden en donde los actores hacen colocaciones de sentido estratégicas, donde el aporte es concurrente y permanente. Es una interacción, una cooperación una red de construcción permanente. Siendo un ideal, sujetos que conforman y modifican la estructura desde la relación con los otros, teniendo un sentido de completud y equifinalidad. Desde el sentido de la habitancia, y ese eco de completud de la comunidad que se forma desde la heterarquía va formando, emerge una identidad especifica, unas orientaciones afinadas hacia el crecimiento y el desarrollo.

La subjetividad como la validación y el reconocimiento del punto de vista del sujeto, entre- 
mezcla condiciones y niveles de su desarrollo como ser social. Aquí una comprensión de los componentes meta-epistemológicos permite la manifestación del mundo en el sujeto. Este mundo que no ha sido solo físico, ni material, sino sensitivo, emocional, mental y espiritual que forman las bases transparentes de su posición de ese ser como sujeto como mundo, en un mundo. Retomando a los sujetos, actores en el acto educativo y en pos de la construcción de un proceso creativo se ha de poner en un mismo nivel el aporte de conocimiento, que cada sujeto (independiente del rol) ha de aportar a esta construcción.

En este punto se pueden vislumbrar las dimensiones desde las cuales, los sujetos en educación (independientes de su rol) se van relacionando, conformando redes y articulando la cimentación del conocimiento. Desde las didácticas contemporáneas se le denomina a este "fenómeno" como Heteroestructura, ya que es un elemento que se va formando desde afuera, en la interacción y va sustentando las condiciones y el entendimiento de cada sujeto y su subjetividad. Se ha de crear un puente entre lo heteroestructurante y la heterarquía, ya que la simulación del modelo educativo desde sus diversas corrientes, plantea siempre el intercambio, el dialogo y la cooperación.

Para dar una mayor relevancia a la creación de un nuevo puente desde el sentido de la interacción y la generación del conocimiento, se plantea el siguiente aparte como el inicio de la reflexión que pretende formalizarse. "En la heteroestructuración, el maestro de diseño ejerce su acción pedagógica en el alumno por medio de una determinada materia. Sin embargo no afronta la responsabilidad que conlleva referirse al proceso de diseño como un fenómeno integral de conocimiento" (Sanchez Ramos, 2008, p. 3).

Los enfoques curriculares, disponen diversas teorías y metodologías, sobre las cuales los sujetos se "adaptan" para aprender. Así encontramos aún enraizadas en las didácticas de diseño que las teorías tradicionales son las que priman en el acto educativo. Planificaciones, objetivos y la eficacia del aprendizaje, se ven manifiestos en los planteamientos teórico - prácticos que desarrollan los estudiantes. Elementos experimentales, que albergaran la memoria pero no lo sentidos, y resultados tangibles que no sufren los procesos catarquicos de un sujeto que surge desde un génesis, y la óptica de un evaluador que determina la validez de las respuestas, y no el carácter de un acto creativo. Sin embargo y en complementación, en las prácticas de los talleres vamos encontrando dinámicas que permiten regular el sentido de comunidad de sentido, donde la conformación va más en la búsqueda del equilibrio, se pone en interacción: la ideología, la concienciación, la liberación y la emancipación, en búsqueda de elementos de creación críticos y no solo operativos.

Desde el sentido Heterarquico y la conformación de comunidades de sentido, el diseño ha de pasar al enfoque del Sujeto que habla, en donde se reconoce: La multiculturalidad, la identidad y alteridad, lo subjetivo, la representación y la lógica del saber cómo poder. Esto visibiliza la emergencia de la Episteme ${ }^{6}$ que alimenta el insight, la base de la creatividad por ende la base de la innovación y la diferenciación.

El acto educativo no son solo dos frentes que se contraponen y contrastan, sino lo que se conforma desde el escenario, en palabras de Nathaniel Hawthorne ${ }^{7}$ : "Dos personas esperan en la calle un acontecimiento y la aparición de los principales actores. El acontecimiento ya está ocurriendo y ellos son los actores" (Hawthorne, 1868). ${ }^{8}$ 


\section{Subjetividad y Creatividad}

Desde las aulas de diseño, en el proceso de intercambio y la construcción del acto educativo, las instancias y lapsos, las confrontaciones y emergencias como los elementos que evidencian la dinámica reflexión o de descubrimiento, dan luces permanentes y diversas ópticas de la creatividad y su esencia en los sujetos y en las "cosas" que se han de crear, los escenarios que están en el futuro y las vidas que vivirán los que están delante (no a la vista) de los proyectistas.

Esas "cosas" que solo emergen a la luz de algún suceso o que solo visualizan y sentimos dependiendo el grado que hayamos alcanzado, o simplemente porque toca aprender y enseñar algo. Así, desde el sentido subjetivo esas inquietudes y contenidos que tiene el sujeto a priori en su conformación, nacen de un cuestionamientos que en la oda de la creación se constituyen como los hilos de la vida que conforma cada sujeto y en si la estructura de las ideas y proyectos que se ponen en la dimensión social para su desarrollo.

Todas estas inquietudes, ideas, conceptos y aprendizajes, siempre dependen de un hecho precedente, y este en el caso en particular del acto educativo desde el diseño, alguna premisa que surge como una problemática, algo que es lo que indiscutiblemente es el traspaso y la sobrevivencia de la herencia no solo biológica, sino sicosocial, material y de supervivencia humana. Al poner un filtro para visualizar lo ontológico, desde este punto de lo que en su individualidad trae el sujeto para la creación, es donde emergen las relaciones de la subjetividad social por ende la validación del sentido Heterarquico, y de la complementación de comunidades para darle sentido a la creación. Los elementos de relación para poder hacer el reconocimiento de una inquietud que nace del sujeto, y que es puesta como referencia inicial para el desarrollo de un proyecto, permite articular el que de la subjetividad en el acto creativo.

Aquí es donde este punto, como inflexión obligaría a rebuscar las experiencias empíricas de la vida de cada sujeto, a lo largo del desarrollo de su existencia -y mas allá de los conocimientos e información académica- para confirmar que el devenir del ser humano, y las conclusiones científicas, son solo una arista de la conformación del conocimiento del sujeto. A su vez las construcciones del complejo sentido de lo espiritual y lo emocional, como diada sublime que permite imprimir elementos particulares y diferenciadores como base de la creatividad. Así:

Todo el material simbólico y emocional que constituye los sentidos subjetivos se produce en la experiencia de vida de la personas, pero no como operaciones que se interiorizan, sino como producciones que resultan de la confrontación e interrelación entre las configuraciones subjetivas de los sujetos individuales implicados en un campo de actividad social y los sentidos subjetivos que emergen de las acciones y procesos vividos por esos sujetos en esos espacios, que son inseparables de las configuraciones de la subjetividad social en la cual cada espacio de vida social está integrado (Gonzalez, 2008, p. 234).

El sujeto en su formación y como parte de la conformación de la subjetividad social siendo partícipe por default de los ordenamientos colectivos desde donde se construye y modela la identidad y el reconocimiento, él hecho descriptivo de la palabra y sus significados y la sensación de ir cumpliendo con los condicionantes de la cultura, enrutandose en las vías unidirec- 
cionales del conocimiento, con las bases de sus ideas y preguntas invisibilizandose, haciéndose ilegibles, y siendo coartadas de a poco por las formulas prefabricadas. Y así en el transcurso del aprendizaje del diseño y el desarrollo de la creatividad, esas ideas van emergiendo, formándose y transformándose desde múltiples enfoques y miradas, y que desde la heterarquía permita la configuración de lo cívico, que se supone prepare para enfrentar, respetar y/o compartir los demás cúmulos de valores infundados, y esa mezcla rara pero existente de la necesidad de sobrevivencia subjetiva como ser humano.

En el desarrollo creativo, y desde el aula de diseño, en donde se anteponen los espacios y los tiempos para la búsqueda de ese "resultado" que impacte al mundo, se le hace necesario a los actores involucrados sobrevivir desde su propia particularidad, y hasta hoy desde los elementos metodológicos para el diseño, como imaginarios y medios concretos para llegar a un resultados, plantean como inquietud si la aplicación de modelos previsibles validan la enseñanza del diseño, y en la visión desde el sentido opuesto, reflexionar como es el aprendizaje del diseño.

La perspectiva heterarquica permitiría visibilizar que la construcción desde las subjetividades particulares, y de la subjetividad social disponen las vías del desarrollo en múltiples direcciones. Por ende no solo aprende quien funge de aprendiz, ni solo enseña quien funge de maestro, se construye en comunidad de sentido y se da una multiplicidad de procesos y enseñanza colectivos. Indagar acerca de las maneras como se ha venido desarrollando desde el aula de diseño el aprender y enseñar, hace que el confrontarse con la objetividad de los resultado permitan romper esos pesados lastres que son como cadenas y que solo a través de esa indagación adquiere el valor de hacerlo, desde lo que permite la reflexión y permite poner en su lugar, las respuestas que solo confrontando como hacemos lo que hacemos nos permite alcanzar alguna aproximación.

Haciendo un recorderis y un ejercicio de observación con los sistemas naturales y con todas las definiciones que creemos conocer y analogamos, o simplemente ni sabemos pero analogamos, (herencia, fuerza, dominancia) ligadas como una razón inherente a nuestro afán histórico de posicionar hábitos y costumbres, y de transmitirlos tratando de vivir con ellos, dejando a nuestro paso construcción y destrucción que no implican propiamente la muerte sino la transformación, llegamos en un orden numérico, no por azar sino por la decisión de pertenecer a algo -coloquialmente como el dicho acerca de que los hijos eligen a sus padres-, y si así fuese se eligen las familias, los valores y probablemente se eligen sus posturas, los modos de aprendizaje, las visiones de la vida y todo lo que necesitamos aprender a raíz de eso, como nuestro foco personal. Todos estos condicionantes particulares mas los condicionantes de cómo desde pequeños aprendemos a aprender nos convierten en sujetos previsibles, y poco maleables.

Así el hombre como un resultante de múltiples vertientes y componentes- se condiciona por los medios y coarta su propia visión y subjetividad. Así:

Todo sistema histórico tiene un proyecto un fundamento radical al que se tiende como aquello que se intenta en todos los actos cotidianos (...) El proyecto es entonces el ser o la esencia de una sociedad, una época, una clase social, un grupo, una familia y hasta una persona singular (Dussel, 1984, p. 193).

Así, solo en ciertos momentos podemos sentir y concluir por ciertos instintos que solo surgen en ciertos esos momentos, citando el párrafo anterior y como se hace en la naturaleza, al mezclarnos para crear vida, porque elegimos o distinguimos ciertas características que queremos 
trascender, y que se resguardan, afirman y crecen desde ese mundo complejo de lo espiritual y que contiene al amor y la pasión.

Desde esta perspectiva se complejiza el proceso porque dejar fusionar la razón y el corazón, con la reacción comportamental heredada de modo biológico o socialmente implementada. Se permite el surgimiento de múltiples variables que pueden ser categorizadas, ordenadas y tal cual como en el hecho de que llegamos a nuestras rutas de vida como ordenes numéricos que en cierta definición pueden ser dados desde el justificación del azar concluyendo que las respuestas y resultados que se dan desde nuestros procesos creativos, son lo que son porque así deben ser.

Pero uno es el orden en que llegamos a los procesos exclusivamente desde lo intuitivo, y otro el orden que sobre el cual vamos acumulando esa intuición y generando conocimiento, a causa de lo que ha precedido nuestra existencia y la existencia de los que forman nuestros esquemas e ideales, complementados con los factores interstructurantes que van generando los lazos con lo que se heteroestructura.

La educación no puede seguir trabajando en al campo de las explicaciones, sino en la relación de las subjetividades, como elementos concurrentes al desarrollo común y por ende al desarrollo particular, en donde el sujeto se compone a sí mismo, se va construyendo, armando y consolidando desde su propia óptica y subjetividad.

El sujeto proviene de su propia historicidad y biografía, de sus propias experiencias vitales, pero el sujeto biográfico no se construye a sí mismo, no emana de un mono-discurso o una monodirección actitudinal. Es un cumulo de experiencias, elementos vitales, adversidades históricas, por ende procesos. El mundo no necesariamente tiene que ser como pensamos, pero podemos construir un mundo desde los procesos que se confrontan en las subjetividades del acto educativo del diseño, en donde se enseña y se aprende desde los lenguajes de la sensibilidad, la ciencia, el arte y la particularidad, vehículo en el que el sujeto va hacia la realidad.

\section{Notas}

1. Analistas Simbólicos. Referente a la especialización excesiva dada a las profesiones y oficios. (Gómez Buendía, 1998).

2. Habitancia: Desde la base conceptual del filósofo alemán Martin Heidegger (1889-1976), los deseos, necesidades y habilidades en el ser humano. Interpretación del autor.

3. Desde la Base de Complejidad sugerida por Edgar Morín (Solana Ruiz, 2005).

4. Con base en el planteamiento de (Skliar, 2007) denominado el "argumento de la Incompletud".

5. Acerca de las palabras de Roger Hudiburg, en su experiencia educativa como docente en el Burbank Junior High School, Boulder, Colorado. Estados Unidos.

6. Desde Michel Foucault: "El punto de partida desde el cual han sido posibles conocimientos y teorías, es el espacio de orden en el que el saber nace, es el fondo, el background que dicta el a priori histórico y determina en qué elemento de positividad han podido aparecer las ideas, constituirse las ciencias, reflexionarse las experiencias en las filosofías, formarse las racionalidades para anularse y desvanecerse quizá pronto." (Tomado de Coreta, Ana, ¿Qué es la Episteme según Michel Foucault? Disponible en http://valeriapuga.blogspot.com/2008/11/ 
qu-es-la-segn-michelefoucault.html).

7. Escritor Estadounidense (1804-1865).

8. Hawthorne, Nathaniel. American Note-Books (1868).

\section{Referencias Bibliográficas}

Bauman, Z. (2001). La Sociedad Individualizada. Madrid: Ediciones Catedra.

Cassirer, E. (1984). Antropología Filosofica. México: Fondo de Cultura Económica.

Dinham, S. (1991). La enseñanza del Diseño: El diseño de la enseñanza. En J. Pericot, Pedagogia del Diseño (págs. 138-149). Barcelona: Gustavo Gilli.

Dussel, E. (1984). Filosofía de la Producción. Bogotá: Editorial Nueva América.

Jung, C. G. (1991). Arquetipos e Inconsciente Colectivo. Barcelona: Paidos - Sicologia Profunda.

Kerényi, K.; Neumann, E.; Scholen, G.; Hillman, J.; Ortiz-Oses, A.; Mayr, F.; Panikkar, R.; Lanceros, P.; (1994). Arquetipos y símbolos colectivos. Circulo Eranos I. Barcelona: Anthropos - Editorial del Hombre.

Larrosa, J. y Skliar, C. (2001). Habitantes de Babel. Politicas y Poieticas de la Diferencia. Buenos Aires: Laertes.

Lazzarato, M. (2006). Por una política menor. Acontecimiento y politica de las sociedades de control. Madrid: Traficantes de sueños.

Maffesoli, M. (1997). Elogio de la Razón Sensible:Una visión intuitiva del mundo contemporáneo. Barcelona: Paidos.

Polo, D. V. (2011). El Desarrollo Humano y la formación integral en diseño. El Desarrollo Humano y la formación integral en diseño (pág. 10). Buenos Aires: Universidad de Palermo.

El Diseño: Intersticio del mundo de la Vida. Una apuesta educativa en la primera infancia. Cali.

Rogers, C., \& Rosenberg, R. (1981). La persona como centro. Barcelona: Editorial Herder.

Sanchez Ramos, M. E. (2008). Las pedagogías del Diseño. En U. d. Palermo, Actas de Diseño 4 (pág. 257). Buenos Aires: Universidad de Palermo.

Skliar, C. (2007). La educación (que es) del otro. Argumentos y desierto de argumentos pedagógicos. Argentina: Ediciones Novedades Educativas.

Solana Ruiz, J. L. (2005). Con Edgar Morin, por un pensamiento complejo. Implicaciones interdisciplinares. Madrid: Ediciones Akal, S.A.

Zemelman, H. (1992). Los Horizontes de la Razón I. Mexico: Anthropos.

Zizek, S. (2006). Organos sin Cuerpo. España: Pre-Textos.

\section{Recursos Electrónicos}

Gonzalez, R. F. (2008). www.usta.edu.co. Recuperado el 20 de Marzo de 2012, de www.usta.edu. co: http://www.usta.edu.co/otras_pag/revistas/diversitas/doc_pdf/diversitas_8/vol.4no.2/ articulo_1.pdf

http://digigel.blogspot.com/2009/05/la-heterarquia.html. (14 de 02 de 2012). 
Summary: What is taught, and what is learned ? Education with its various aspects as systematic reflection, a compendium of training methods for a particular context, in itself has become a stream of potential pragmatic, efficient and conclusive, that have framed the subject in a container of knowledge, as operative entities from the reactions driven by an impulse or case study, and not in a system that tends to complementarity, unity and overall benefit from the sensitive and vital perspective. In this wide spectrum of possibilities, the validity of teaching and learning leads in to recognize as a fundamental premise for a subject, a man or woman in a society that has faced since the classroom to have more than knowledge and the central axis of their work, their role, and has been structured from the essence of education and the human condition. This paper raises from the perspective of designing a reflection on the elements of structure and power, which are given from classroom design and from the roles of both Teacher and Student, where the creative emergency search not only the differentiation of tangible-product-design process, but the recognition of subjects whom through the educational help others to be.

Key words: Design - Education - heterarchy - human development.

Resumo: ¿Que se ensina, e que se aprende? A educação com suas diversas vertentes como a reflexão sistemática, compendio de métodos formativos para um contexto particular, em si mesma se converteu numa corrente de possibilidades pragmáticas, eficientes e conclusivas, que emolduraram ao sujeito num contentor de conhecimentos, como entes operantes desde as reações guiadas por um impulso o caso de estudo, e não num sistema que propenda complementaridade, unidade e beneficio geral, desde a perspectiva sensível e vital. Neste grande espectro de possibilidades, a validez do ensinar e do aprender está em reconhecer como premissa fundamental a um sujeito, a um homem ou mulher de uma sociedade, que se tinha confrontado desde a aula a ter mais que conhecimentos e o eixo central da sua tarefa, do seu rol, e tem sido estruturado desde a essência na educação e da condição humana. Este escrito estabelece, desde a óptica do design, uma reflexão em torno aos elementos de estrutura e poder, que se dão desde as aulas de design e desde os roles de aqueles que as ocupam (professor-estudante), onde a emergência criativa procura não somente a diferenciação dos resultados tangíveis -produto do processo de design- senão o reconhecimento dos sujeitos que por meio do ato educativo ajudam a ser aos outros.

Palavras chave: desenvolvimento humano -Design - educação - heterarquia. 